\title{
The effect of modal properties of crash box structures with trigger mechanisms towards the crashworthiness by using finite element analysis
}

\author{
M.N.A.M. Asri' ${ }^{1}$ N.A.Z. Abdullah ${ }^{1}$ and M.S.M. Sani ${ }^{1,2, *}$ \\ ${ }^{1}$ Advanced Structural Integrity \& Vibration Research (ASIVR), Faculty of Mechanical and Automotive Engineering Technology, \\ Universiti Malaysia Pahang, 26600, Pekan, Pahang, Malaysia \\ Phone: +6094246325 ; Fax: +6094242202 \\ ${ }_{2}$ Automotive Engineering Centre, Universiti Malaysia Pahang, 26600, Pekan, Pahang, Malaysia
}

\begin{abstract}
In the automotive structure, there are different components that utilise aluminium alloy $(\mathrm{AA})$ sheets and it is used widely in the car body-in-white which comprise bumpers and the crash box structure at the front end of the car which specifically designed to withstand the event of collision. As the structures are also experiencing dynamic loading, it were also a concern for the structures to show satisfied modal properties. In this study, the modal properties of the crash box structures are investigated along with the effect of the modal properties towards the crashworthiness behaviour of the structure itself with the approach of finite element analysis. Experimental modal analysis was also done to further validating the finite element analysis of the modal properties. Three different designs of trigger mechanisms are applied towards the crash box structure to observe on both findings. For the connector element, equivalent nodes of both parts of the crash box structures are used. For the results, the correlation from both findings did show that the presence of trigger mechanism did decreased the magnitude of natural frequencies as well as the mode shape as shown by crash box type 3 by $9.50 \%$ and for the crashworthiness output, the crashworthiness behaviour of the crash box with trigger mechanisms were better in term of the collisions phases indicated by the primary peak force and the secondary peak force from the forcedisplacement curve as also shown by crash box structure type 3 with the percentage of $22.59 \%$. The study does shows that the stiffness and mass distribution due to the presence of trigger mechanism do affect the modal properties of a structure as well as its crashworthiness output.
\end{abstract}

ARTICLE HISTORY

Received: $15^{\text {th }}$ Feb 2021

Revised: 09th Sept 2021

Accepted: $20^{\text {th }}$ Sept 2021

\section{KEYWORDS}

Crash box;

trigger mechanism;

finite element analysis;

computational modal

analysis;

computational crash

analysis.

\section{INTRODUCTION}

Body structure of a vehicle consists of several important compartment which are the occupant cell, front-end, rearend and body add-on parts. Reviewing the vehicle as a whole, one of the vital aspect for a vehicle is the need for the structure to protect the occupants during any case of collision that caused by accidents as well as providing the good quality of noise, vibration and harshness (NVH) towards the occupants. Most of the modern vehicles, focusing on the automobile or car, the application of lightweight based materials is becoming more crucial as the demand in developing cars with low weight and fuel efficient are becoming the centre of interest in manufacturing a car [1, 2]. Due to the reasons, aluminium has been used in automotive production which mainly used for the component of car chassis, doors, and panels. This is because aluminium owns the aspect of sufficient strength, better formability, light weight, and good crashworthiness behaviour [1].

The uses of aluminium in the car chassis, such as the component of the front-end of a car which is the crash box have research by numerous researches [3-5] as the structure of crash box are well-known to be one of the important structure in the event of frontal collision besides the bumper itself. From time to time, the crash box structure is being researched with various design and configuration in order for the structure to retain good crashworthiness properties [4], [6]. One of the configurations that are found to be enhancing the crashworthiness properties of the crash box structure are the application of trigger mechanism [7-10] Trigger mechanism is the introduction notches or holes towards the structures. By having trigger mechanism, the crash box structure is found to exhibits low initial peak force when subjected towards axial loading or oblique loading [11-13]. The trigger mechanism also could initiate the structure to buckle in a controlled manner and stable collapsing mode instead of the global bending or uncontrolled types of buckling. This could be achieved efficiently if the trigger mechanism is located on a correct location within the structure [14]. As the crash box structure are located at the front end where the engines and the front wheels lies, the structure also experiencing dynamic load which it also need to be taken into account so that the crash box structure with trigger mechanism design and configuration are satisfied for the NVH aspect which is the modal properties. For a trigger mechanism design of rectangular windows introduced towards the crash box by [15], a significant reduction in the magnitude of initial peak load and it also enable the initiation of the buckling to occur much faster than conventional crash box structure. In the other studies done by [10], it was found that the crown type trigger mechanism managed to obtain a reduction of $30 \%$ in initial peak load compared to conventional crash box structure. Such trigger mechanism also gave a $309 \%$ of performance 
funcation coampared to other crash box structure configuration which were chamfer trigger and fillet trigger for $144 \%$ and $109 \%$ respectively.

It could be found that in order to appease both aspect of NVH and crashworthiness, several studies were found to utilise the method of multidisciplinary optimization such as in [16, 17]. As in the studies of [17], the optimization is regarding on reducing the thickness of the specific components of a car so that an optimum mass of the structure is achieved with respect to the design criteria from the crashworthiness constraint of crush energy and displacement as well as the torsional frequency characteristic from the modal analysis where the result shows a reduction of 5\% mass from the baseline design plus the reduction in computational costs. There was also an optimization method of utilizing finite model updating technique on a crash box structure as the studied done [18] where it was found that model updating technique did affect the crashworthiness output of the structure.

This paper on the other hand is attempted to conduct finite element analysis (FEA) on both modal analysis and crashworthiness study in order to observe on the significance of various design of trigger mechanism of the crash box structures towards the modal properties of the structures itself. By the end of the study, different trigger mechanism presence on the crash box structures yields different magnitude of natural frequencies and mode shape due to the differ in stiffness and mass distribution of the crash box structures.

\section{MODAL ANALYSIS}

In order to facilitate this study, the crash box structures are represented by two different parts which are the top-hat profile structure and the flat rectangular base structure as shown in Figure 1. The configuration of the crash box in this study are based on regular car front-end chassis structure which are then connected through the connecting element of nodes equivalence. The material used for both parts are the aluminium alloy sheet (AA) 6061 with a uniform thickness of $1.5 \mathrm{~mm}$. The finite element (FE) models of the structures were created by using SolidWorks as surface. MSC Patran was then further utilised to assign the material properties, meshing elements as well as joining elements. The material properties assigned are as in Table 1. For the modelled crash box structure, the structures were produced from two different parts and assembled together with the connecting element of equivalence nodes where the side edge nodes of the upper parts and the lower base parts are connected together in which instead of two different nodes, only a single node was used to resemble both parts as a whole crash box structures. Figure 2 shows on the nodes equivalence at the side edge of the structure model with only ten nodes are chosen to be equivalence. As the structures were set-up to be response freely with no constraint, the FE model was set-up to be in a free-free boundary condition.

Validating the FEA of the crash box structures, the experimental modal analysis (EMA) was also done towards the three types of crash box structures by using the experimental setup of impact hammer and roving accelerometer with the same free-free boundary condition so that the FE models of the crash box could be used for the computational crashworthiness analysis.

With the purpose of to study the effect of triggering element towards both studies of modal analysis and crashworthiness, the crash box structures used for the finite element analysis were three structures which are one regular crash box (type 1) as in Figure 1 while the other two are the crash box structure with different trigger mechanism which are the rectangular type trigger (type 2) and the edge slotted trigger (type 3) as shown in Figure 3. The selection criterion of the structures is based on the crashwrothiness output of the trigger mechanism configuration and design obtained from the previous studies where the findings in the crashworthiness studies show that the presence of trigger mechanism with specific configuration and design would signifcanly affect the crashworthiness output of the structure itself such as the type 2 and type 3 trigger mechanism.

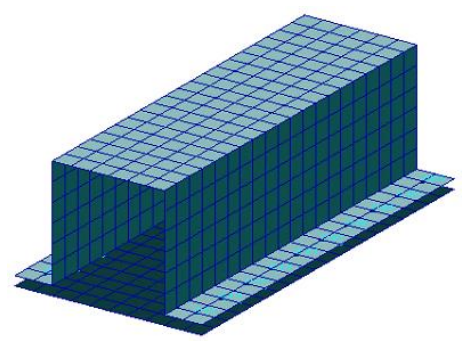

Figure 1. FE model of crash box structure type 1 


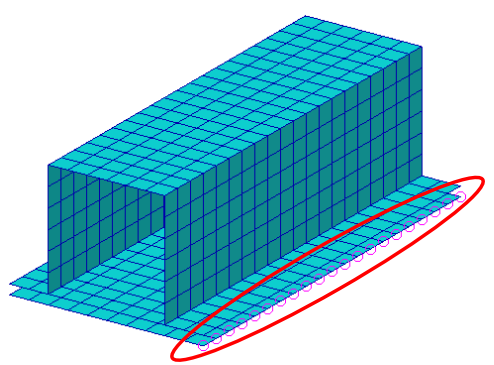

Figure 2. Equivalence nodes location

Table 1. Input properties of material

\begin{tabular}{cc}
\hline Properties & Values \\
\hline Material & Aluminium Alloy (AA) 6061 \\
Young's modulus (GPa) & 68.9476 \\
Poisson ratio & 0.33 \\
Density $\left(\mathrm{kg} / \mathrm{m}^{3}\right)$ & 2700 \\
Thickness $(\mathrm{m})$ & 0.0015 \\
\hline
\end{tabular}
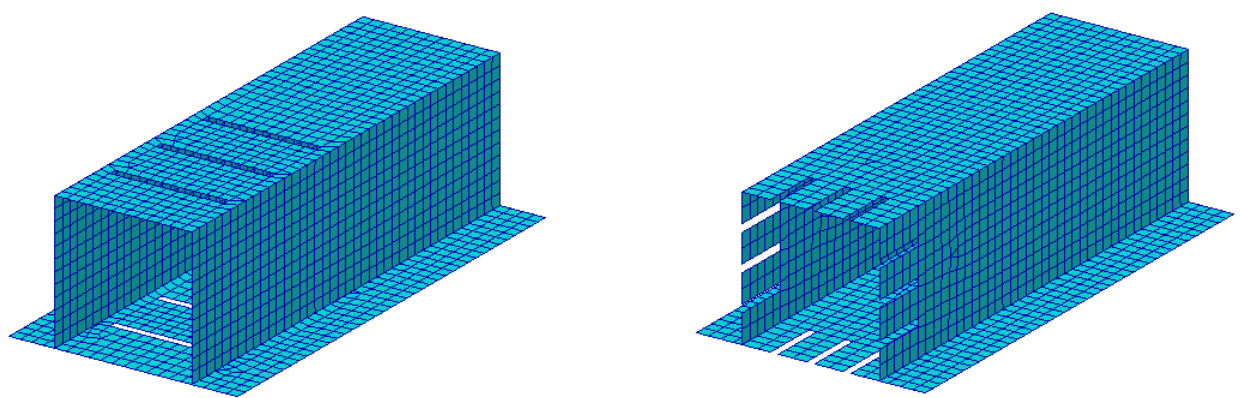

Figure 3. Crash box structure with trigger mechanism type 2 and type 3

The Table 2 below shows the natural frequencies of the three crash box structures. The computational modal analysis is calculated numerically derived from the general equation of motion of:

$$
M x(t)+C x(t)+K x(t)=f(t)
$$

where $M$ is mass, $C$ is damping and $K$ is stiffness. As for this study, the damping and force were neglected hence, the equation would be as follows:

$$
M x(t)+K x(t)=0
$$

By using complex notation, the above equation could be expressed as:

$$
\begin{gathered}
x(t)=X e^{n \omega t} \\
\ddot{X}(t)=-\omega^{2} X e^{n \omega t}
\end{gathered}
$$

And substituting back the complex notation in the Eq. (2), then the natural frequencies would be obtained.

$$
\omega_{n}=\sqrt{k / m}
$$

where $\omega_{n}$ is natural frequency, $k$ is stiffness and $m$ is mass. 
Table 2. Natural frequencies of the crash box structure

\begin{tabular}{cccccccccc}
\hline & \multicolumn{9}{c}{ Natural Frequency } \\
\cline { 2 - 10 } Modes & \multicolumn{3}{c}{ Type 1 } & \multicolumn{3}{c}{ Type 2 } & \multicolumn{3}{c}{ Type 3 } \\
\cline { 2 - 10 } & FEA $(\mathrm{Hz})$ & $\begin{array}{c}\text { EMA } \\
(\mathrm{Hz})\end{array}$ & $\begin{array}{c}\text { Error } \\
(\%)\end{array}$ & FEA $(\mathrm{Hz})$ & $\begin{array}{c}\text { EMA } \\
(\mathrm{Hz})\end{array}$ & $\begin{array}{c}\text { Error } \\
(\%)\end{array}$ & FEA $(\mathrm{Hz})$ & $\begin{array}{c}\text { EMA } \\
(\mathrm{Hz})\end{array}$ & $\begin{array}{c}\text { Error } \\
(\%)\end{array}$ \\
\hline 1 & 527.17 & 695 & 24.15 & 519.61 & 601 & 13.54 & 448.73 & 601 & 25.34 \\
2 & 539.15 & 690 & 21.86 & 534.33 & 648 & 17.54 & 529.71 & 698 & 24.11 \\
3 & 933.21 & 1240 & 24.74 & 922.19 & 1225 & 24.72 & 857.30 & 947 & 9.47 \\
4 & 1024.60 & 1330 & 22.96 & 1005.40 & 1300 & 22.66 & 992.76 & 1010 & 1.71 \\
5 & 1298.00 & 1520 & 14.61 & 1238.00 & 1360 & 8.97 & 1112.51 & 1280 & 13.09 \\
6 & 1602.80 & 1620 & 1.06 & 1559.00 & 1570 & 0.70 & 1364.71 & 1420 & 3.89 \\
\hline
\end{tabular}

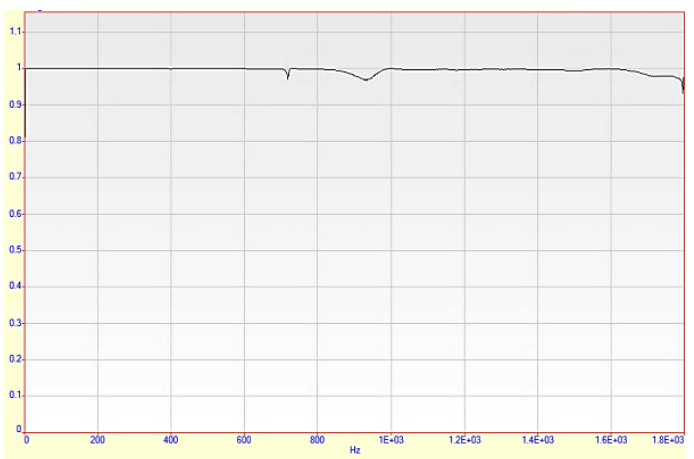

(a)

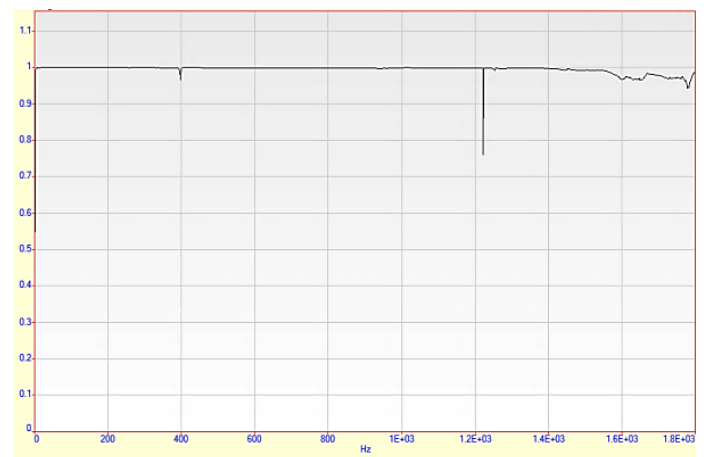

(b)

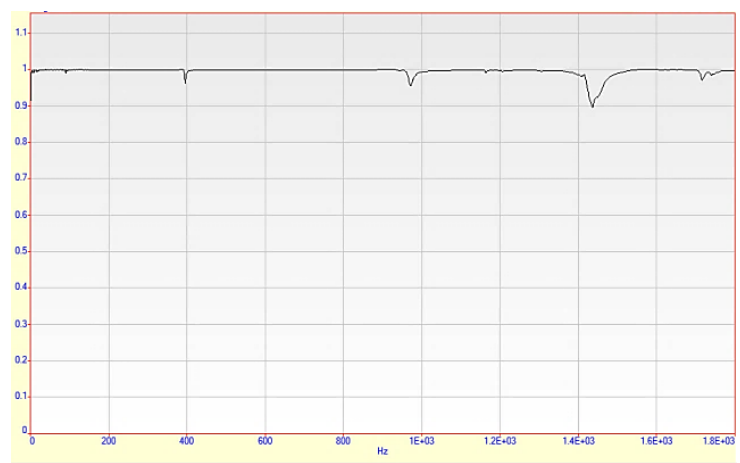

(c)

Figure 4. Coherence graph of EMA for: (a) crash box structure type 1, (b) crash box structure type 2 and (c) crash box structure type 3

For the FEA results, evaluating on the crash box type 1, 2 and 3, it could be noticed that the crash box structures type 1 did yield a higher in magnitude for the natural frequencies followed by the type 2 and 3 . The difference between the magnitude of type 1 and type 2 are relatively small but significantly differ for type 3 while the EMA done towards the crash box structures did show that the value of EMA for all type of crash box structures are below $25 \%$ gap of error for some magnitude of natural frequencies while most of the error are below $20 \%$. Such value of error may be sourced from the inaccuracy of the joining element used to resemble the actual resistance spot weld of the crash box structures. Evaluating the results generally, it could be observed that the magnitude of natural frequencies is alike where the crash box structure type 1 did imply the highest magnitude of natural frequencies followed by the type 2 and type 3 which the results were in a close agreement with the trend of magnitude for natural frequencies yield by the FEA. Although the gap of error between the FEA and the EMA could be further improved, the baseline for the FE model of the crash box structures could be used to further evaluate the structures for the crashworthiness analysis. Figure 4 above shows the coherence graph obtained from EMA for all crash box structures.

The difference for each of the crash box structure would closely relate to the above natural frequency equation as in Eq. (3) which may be affected by the stiffness or mass. The effect of stiffness distribution towards the dynamic behaviour of a structure had been studied as well by [19, 20]. For the study done by [19], it was related toward the structure of perforated flexible plane. Various design of experiments was used in the study, and it was observed that the concentration 
of perforation did give an effect towards the vibration behaviour of the flexible plate. There were also studies indicating the effect of shifting concentrated mass towards the vibration aspect of a structure such as [21-23].

Table 3. Mode shape of the crash box structures

\begin{tabular}{|c|c|c|c|}
\hline \multirow{2}{*}{ Modes } & \multicolumn{3}{|c|}{ Mode Shape } \\
\hline & Type 1 & Type 2 & Type 3 \\
\hline 1 & & & \\
\hline 2 & & & \\
\hline 3 & & & \\
\hline 4 & & & \\
\hline 5 & & & \\
\hline 6 & & & \\
\hline
\end{tabular}

Table 3 above shows the mode shape of all crash box structures. The countours do indicates on the displacement of the structural mode shape. From the mode shape results, it could be identified that the first mode shape was bending mode, second mode shape was torsional mode and the third until the sixth mode shape are complex modes. For crash box structure type 1 and type 2, the first mode shape to sixth mode shape were alike where the mode shape did affects the whole crash box structure while for crash box structure type 3, only the first two mode shapes were affecting the entire structure, while for the complex mode shapes, the deflection of the structure is only affecting the trigger mechanism at the front end of the structure.

\section{COMPUTATIONAL CRASH ANALYSIS}

The FEA analyses for crashworthiness were done for all type of the crash box structures. From the crashworthiness analysis, there could be observe on the relevance of introducing the trigger mechanism towards the crash box structures. These crashworthiness analyses were run through the software of Abaqus instead of MSC Patran/Nastran as Abaqus was much widely used by reserachers in crashworthiness studies as well as Abqaus was much easier in term of to setup the whole analyses and obtaining the data for post analyses study. The set-up for the FEA was explicit quasi-static analysis as in order to observe the result from the baseline models of the crash box structures. As in Figure 5, the rear-end of the model was fixed with a pinned rigid plate while the front end of the structure was allowed to receive the load force with 
a displacement of half the length of the modelled structure which is $100 \mathrm{~mm}$ with the main purpose of observing on the buckling behavior of the crash box model especially the structure with the trigger mechanism. The time step was set to $2 \mathrm{~ms}$.

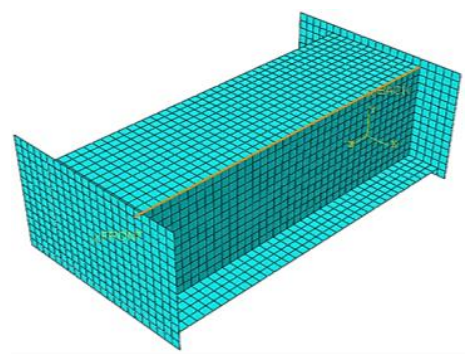

Figure 5. Crash analysis setup for crash box structure type 1

From the FEA of crashworthiness for all the crash box structure, the main crashworthiness parameters that were compared are force against displacement. Figure 5 below shows the force against displacement curve for the three types of the crash box models. The curves obtained for the three different models of the crash box structures were overlaid as to show on the effect of different trigger mechanisms towards the peak force of the structure upon the buckling process. Table 4 shows the magnitude of the primary peak force and the secondary peak force as could be observed from the below curve.

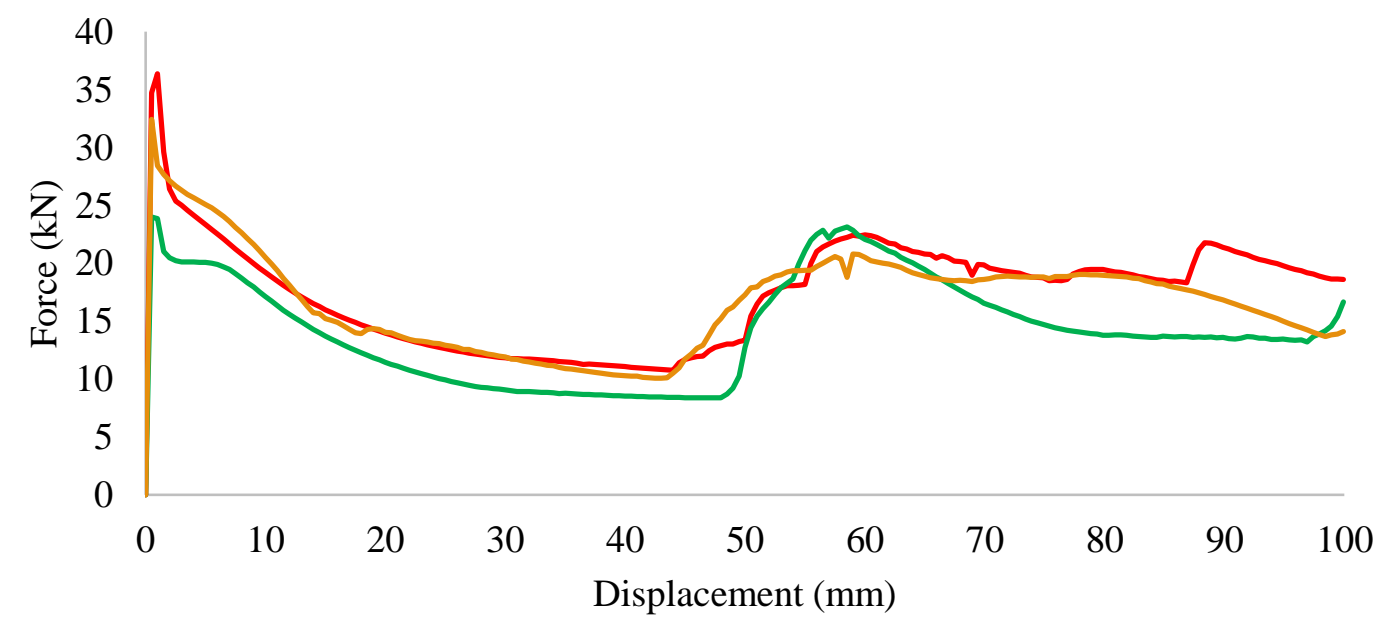

- Type 1 Type 2 Type 3

Figure 6. Axial force against displacement curve

Table 4. Primary peak force of all crash box structure

\begin{tabular}{ccccc}
\hline Type & $\begin{array}{c}\text { Primary Peak Force } \\
(\mathrm{N})\end{array}$ & $\begin{array}{c}\text { Secondary Peak Force } \\
(\mathrm{N})\end{array}$ & $\begin{array}{c}\text { Energy Abssorbed } \\
(\mathrm{J})\end{array}$ & $\begin{array}{c}\text { Percentage Improvement } \\
\text { of Energy Absorbed }(\%)\end{array}$ \\
\hline 1 & 36363.0 & 22468.7 & 1661272.89 & 0 (base value) \\
2 & 23991.0 & 23139.2 & 1422301.82 & -14.38 \\
3 & 32420.7 & 20783.2 & 1743554.74 & 22.59 \\
\hline
\end{tabular}

As shown by the above curve, it could be identified that the first peak from the curve which was the peak crash load, or also known as primary peak force in which it is the maximum force developed during the axial loading process towards the structure or in general, when the structure do oppose the deformation occurred within the structure, the force level would have a rise as in the curve. The deformation would be the first fold of the structure during buckling process [12, $24,25]$. The next fold is indicated with the secondary peak force and for each fold that occur would yield an oscillation in the force-displacement curve.

To obtain the total energy absorption, E, it would depend on the area under the curvature as in Figure 6. The region before the primary peak force would be region for pre-crushing process while the region after that would refer to the postcrushing process according to [26]. Hence, the governing equation would be on the calculation of integration of force: 


$$
E=\int_{S_{i}}^{S_{f}} P(s) d s
$$

Where $P$ is the force, $S_{i}$ and $S_{f}$ are the initial and final displacement of the post-buckling process respectively. From the integration equation also could be used to obtain other crashworthiness parameter such as mean crush load, $P_{m}$, crashing load efficiency, $\eta_{f}$ and specific energy absorb, $E_{s}$ as well as shown in Eq. (2), (3) and (4).

$$
\begin{gathered}
P_{m}=\frac{E}{S_{f}} \\
\eta_{f}=100\left(P_{m} / P_{i}\right) \\
E_{s}=\frac{E}{m_{\text {crush }}}
\end{gathered}
$$

From the curve, it can be observed that the highest peak force was yielded by the crash box structure type 1 which is without the trigger mechanism with the value of $36.3 \mathrm{kN}$. With the presence of trigger, the peak forces are relatively lower for type 2 and type 3 which were $23.9 \mathrm{kN}$ and $32.4 \mathrm{kN}$ respectively. As had been studied by [25], it is also important to identified the magnitude of secondary peak force. This is because the difference between primary and secondary peak force in the force-displacement curve could determine on the amount of total energy absorbed based on the area under the curvature. As for this curve, it could be stated that the type 3 crash box structure showed the highest total energy absorb $1743.55 \mathrm{~kJ}$ compared to type 1 and type 2 which were $1661.27 \mathrm{~kJ}$ and $1422.23 \mathrm{~kJ}$ respectively due to the condition that the area under the curve was larger thus the amount of total energy absorbed are higher during such period of time. As the crash box structure type 1 was a crash box structure without trigger mechanism, it was considered as a baseline model and thus the absorbed energy was also a base value to be correlated to the other crash box structure with trigger mechanism. Crash box structure type 3 did show a higher percentage of improvement for energy absorbed by $22.59 \%$ compared to crash box structure type 2 with the decereasing percentage of $14.38 \%$. The decreasing percentage would be on the factor of the location of trigger mechanism which were not properly located on the buckling area of the crash box structure [27]. The presence of trigger mechanism type 3 with proper design and configuration did prove that the presence of trigger mechanism had improved the crashworthiness behaviour of the structure upon receiving impact.

Table 5 below shows on the qualitative comparison of deformation of all crash box structures. The presented comparison was through the sequential deformation taken for every 0.03 seconds of time steps. It could be observed that the presence of trigger mechanism did initiate the deformation of the structure during the buckling process compared to the type 1 crash box structure. It was observed that for crash box structure type 1, the buckling was started to occur at the middle of the structure followed by the backside of the structure before it would completely deform and the deformation pattern was relatively in an uncontrolled manner. Compared towards crash box structures type 2 and type 3 , the observation made was that the crash box structure type 2 did deformed in a more controlled manner where the deformation started to occur at the location of trigger mechanism and the second fold of deformation started to occur just at the backside of the structure's triggering element itself as assumed. Meanwhile, for crash box structure type 3 , it were discerned to start deformed improperly as in step time $0.12 \mathrm{~s}$ where the trigger mechanism at the front-end did trigger the deformation to take place at the front side of the crash box structure before improperly buckle due to the no trigger mechanism at the back side part of the structure itself. From the comparison, it could be found that there are double buckling processes that occurred upon applying the load in which the first buckling occurred at the trigger mechanisms located at the front-end of the crash box structures while the next buckling process occurred at the back-end of the crash box structures where there were no trigger mechanism introduced at the region. This justification did eventually validate on the significant difference of the primary peak force compared to the secondary peak force of the force-displacement curve. Hence, the introduction of trigger mechanism by the structures were found to be greatly assist on the pattern of deformation upon receiving the impact. 
Table 5. Sequential strain deformation shape of crash box under quasi-static loading

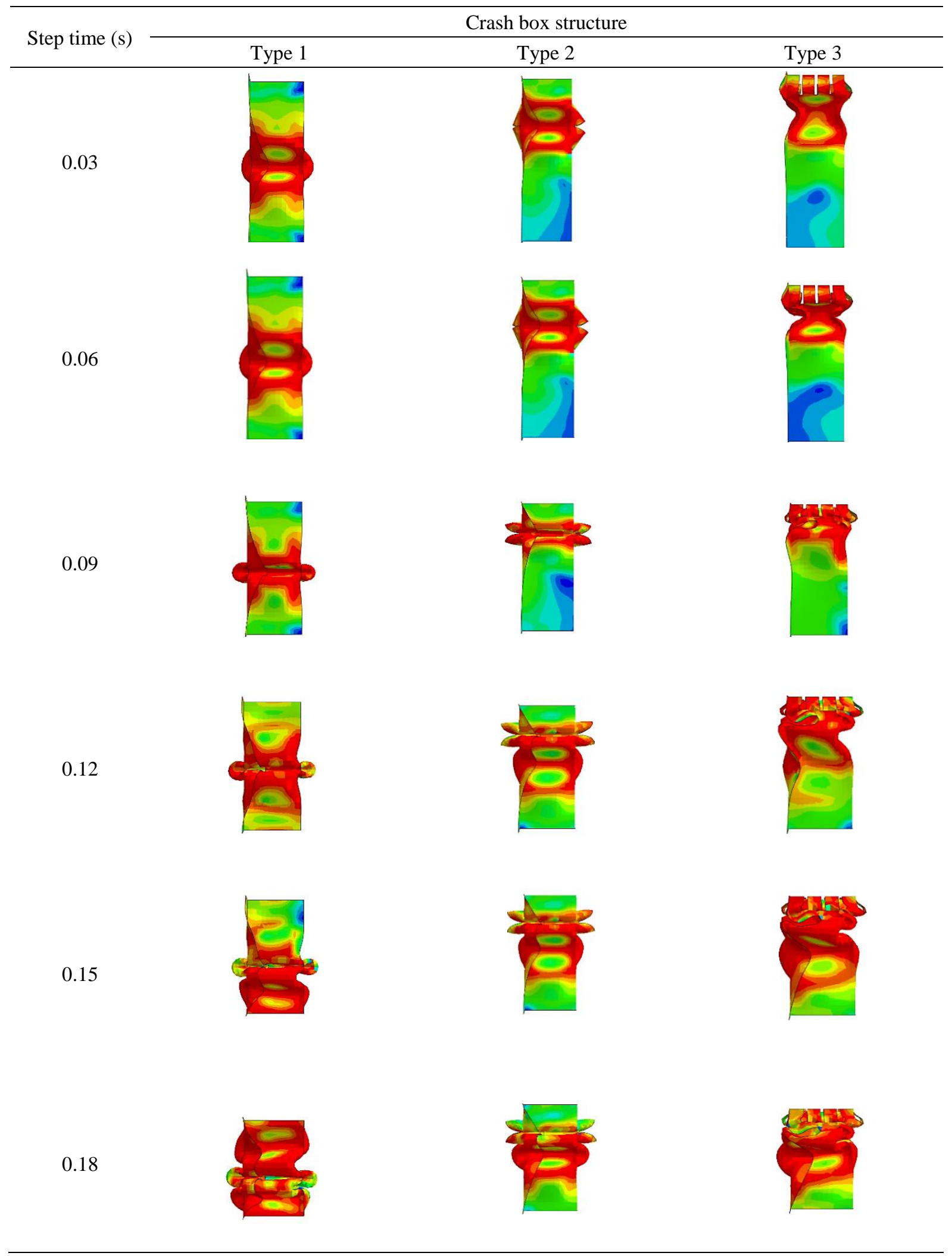

The assembly of the two parts of top-hat plate and the base plate in order to form a structure of crash box by applying the connecting elements were found to be intently imitate the practical crash box structures. In FEA focusing on MSC Patran, there are several joining methods which indicated by the connecting element of CWELD, CFAST, CBEAM, CBAR and more others and it does depend on the type of joining to be used at the structures practically. To apply on the best connecting element in FEA, the connector chose should be correlated with the experimental result [26, 28-30]. As had been stated before, the stiffness and mass distribution of the structures would affect both modal behaviour as well as the crashworthiness output. Besides on than the existence of the trigger mechanism within the structure, the joining methods are also affecting the stiffness such as the welding and the bolted connection in an assembly [25, 26, 28]. For 
this study, the effect of stiffness and mass distribution towards the modal analysis could be observe for crash box structure type 1 which it was the stiffest and heaviest structure among the other structure which explain the highest natural frequency yield for the modal analysis. Eventually, the stiffer and heavier structure would produce the highest peak force as in the curve in Figure 5 which in crashworthiness aspect, it would cause a high intensity deceleration which is a critical safety aspect towards the occupant perspective.

\section{CONCLUSIONS}

This paper has shown that for the modal analysis, the highest magnitude for natural frequency are shown by the crash box structure type 1 . For the crashworthiness, it is in correlation with the studies of trigger mechanism where the introduction of trigger mechanism within the crash box structure do improve on the aspect of energy absorption and the manner of deformation. It could be deduce too that higher magnitude of natural frequencies are on the crash box structure without triggering mechanism and it do affect the crashworthiness aspect of primary peak force when subjected to axialloading where this indicated that stiffness and mass did affect the magnitude of the natural frequency as well as the crashworthiness output. Higher stiffness and mass of a structure did yield a high natural frequencies for modal analysis and it did effect the primary peak force to be higher for crashworthiness study. This research would be considered as the base for further studies regarding on the relation between modal analysis and crashworthiness study. As this paper was only conveying the results obtain from the FEA, further analysis regarding on both modal analysis and crashworthiness study should be done which it should include the experimental analysis as well so that the results obtain from FEA could be correlated. An optimization method such as model updating could also be done to observe in detail on the consequences of altering the properties that would affect the stiffness and mass for both modal behaviour and crashworthiness aspects.

\section{ACKNOWLEDGMENTS}

The authors of this paper would like to acknowledge a great support and encouragement by focus group of Advanced Structural Integrity of Vibration Research (ASIVR), Universiti Malaysia Pahang (UMP) for providing all the equipment used for this work Fundamental Research Grant Scheme (FRGS/1/2017/TK03/UMP/02-19) - RDU 170123 and Postgraduate Research Grant - PGRS190304

\section{REFERENCES}

[1] L. W. Cheah, "Cars on a diet: The material and energy impacts of passenger vehicle weight reduction in the U.S," $\mathrm{PhD}$ Thesis, Massachusetts Institute of Technology, 2010.

[2] D. Anselm, "The passenger car body: Design, deformation characteristics, accident repair," Vogel, 2000.

[3] D. D. Desai and M. A. Kadam, "Analysis and development of energy absorbing crash box," Int. J. Adv. Res. Innov. Ideas Educ., vol. 2, no. 3, pp. 3776-3782, 2016.

[4] M. S. Zahran, P. Xue, M. S. Esa, and M. M. Abdelwahab, "A novel tailor-made technique for enhancing the crashworthiness by multi-stage tubular square tubes," Thin-Walled Struct., vol. 122, pp. 64-82, 2018.

[5] A. Segade, A. Bolaño, J. A. López-Campos, E. Casarejos, J. R. Fernandez, and J. A. Vilán, "Study of a crash box design optimized for a uniform load profile," in IRF2018: 6th Int. Conf. Integrity-Reliability-Failure, 2018, Portugal.

[6] N. A. Z. Abdullah, M. S. M. Sani, M. S. Salwani, and N. A. Husain, "A review on crashworthiness studies of crash box structure," Thin-Walled Struct., vol. 153, p. 106795, 2020.

[7] C. Zhou et al., "The energy absorption of rectangular and slotted windowed tubes under axial crushing," Int. J. Mech. Sci., vol. 141, pp. 89-100, 2018.

[8] H. Nikkhah, F. Guo, Y. Chew, J. Bai, J. Song, and P. Wang, "The effect of different shapes of holes on the crushing characteristics of aluminum square windowed tubes under dynamic axial loading," Thin-Walled Struct., vol. 119, pp. 412-420, 2017.

[9] H. Nikkhah, A. Baroutaji, and A. G. Olabi, "Crashworthiness design and optimisation of windowed tubes under axial impact loading," Thin-Walled Struct., vol. 142, pp. 132-148, 2019.

[10] M. Jahani, H. Beheshti, and M. Heidari-Rarani, "Effects of geometry, triggering and foam-filling on crashworthiness behaviour of a cylindrical composite crash box," Int. J. Automot. Mech. Eng., vol. 16, no. 2, pp. 6568-6587, 2019.

[11] M. S. I. S. Dawood, A. L. A. Ghazilan, and Q. H. Shah, "Finite element analysis of a composite crash box subjected to low velocity impact," IOP Conf. Ser. Mater. Sci. Eng., vol. 184, no. 1, 2017.

[12] A. S. Kalshetti and S. V. Patil, "Energy absorption of varying thickness rectangular section crash box for quasi-static axial loading," Int. Eng. Res. J., pp. 387-391, 2015.

[13] D. F. M. Silva, C. M. A. Silva, I. M. F. Bragança, C. V Nielsen, L. M. Alves, and P. A. F. Martins, "On the performance of thin-walled crash boxes joined by forming," Materials (Basel), vol. 11, no. 7, 2018.

[14] Y. Kitagawa, L. Hagiwara, and M. Tsuda, "Development of a collapse mode control method for side members in vehicle collisions," SAE Tech. Pap., 1991.

[15] C. Zhou et al., "The energy absorption of rectangular and slotted windowed tubes under axial crushing," Int. J. Mech. Sci., vol. 141, pp. 89-100, 2018. 
[16] P. Adduri, J. P. Leiva, G. Quinn, and B. C. Watson, "Car body optimization considering crashworthiness , NVH and static responses," 13th Int. LS-DYNA Users Conf., pp. 1-8, 2014.

[17] F. Duddeck, "Multidisciplinary optimization of car bodies," Struct. Multidiscip. Optim., vol. 35, no. 4, pp. 375-389, 2008.

[18] N. A. Z. Abdullah, M. S. M. Sani, and M. S. Salwani, "Comparison of crash behaviour prediction of a car crash box using initial and updated finite element model," J. Phys. Conf. Ser., vol. 1262, no. 1, 2019.

[19] A. Putra, Y. M. Cheah, N. Muhammad, A. Rivai, and C. M. Wai, "The effect of perforation on the dynamics of a flexible panel," Adv. Acoust. Vib., vol. 2014, 2014.

[20] M. Qiu, D. Wang, H. Wei, X. Liang, and Y. Ma, "Vibration modal analysis and optimization of the motor base," MATEC Web Conf., vol. 175, pp. 1-4, 2018.

[21] N. Hossain, M. S. Islam, K. N. Ahshan, and M. Z. Hossain, "Effects on natural frequency of a plate due to distributed and positional concentrated mass," J. Vibroengineering, vol. 17, no. 7, pp. 3751-3759, 2015.

[22] C. G. Boay, "Frequency analysis of rectangular isotropic plates carrying a concentrated mass," Comput. Struct., vol. 56, no. 1, pp. 39-48, 1995.

[23] K. D. Mali and P. M. Singru, "Determination of the fundamental frequency of perforated rectangular plates: Concentrated negative mass approach for the perforation," Adv. Acoust. Vib., vol. 2013, 2013.

[24] Z. Gronostajski and S. Polak, "Quasi-static and dynamic deformation of double-hat thin-walled elements of vehicle controlled body crushing zones joined by clinching," Arch. Civ. Mech. Eng., vol. 8, no. 2, pp. 57-65, 2008.

[25] N. N. Hussain, S. P. Regalla, and Y. V. D. Rao, "Comparative study of trigger configuration for enhancement of crashworthiness of automobile crash box subjected to axial impact loading," Procedia Eng., vol. 173, pp. 1390-1398, 2017.

[26] Ö. Özbek, Ö. Y. Bozkurt, and A. Erklig, "Crashworthiness of basalt fiber reinforced composite pipes subjected to quasi-static lateral compression," in UEMK Proceeding Book, pp. 531-541, 2019, Turkey.

[27] M. D. White and N. Jones, "Experimental study into the energy absorbing characteristics of top-hat and double-hat sections subjected to dynamic axial crushing," Proc. Inst. Mech. Eng. Part D J. Automob. Eng., vol. 213, no. 3, pp. 259-278, 1999.

[28] N. A. Nazri and M. S. M. Sani, "Joining strategy analysis of structural dynamic in top hat plate of dissimilar materials," $J$. Phys. Conf. Ser., vol. 1262, 2019.

[29] N. M. Hassin, M. A. Yunus, M. N. Abdul Rani, M. S. A. Sulaiman, W. I. I. Wan Iskandar Mirza, and A. A. Mat Isa, "Experimental and finite element analysis of riveted joints structure of a simplified model of aluminium crash box," J. Eng. Appl. Sci., vol. 11, no. 7, pp. 1451-1455, 2016.

[30] N. A. Z. Abdullah, M. S. M. Fouzi and M. S. M. Sani, "Computational modal analysis on finite element model of body-inwhite structure and its correlation with experimental data," Int. J. Automot. Mech. Eng., vol. 17, no. 2, pp. 7915-1726, 2020. 